\title{
Inequity in dialysis related practices and outcomes in Aotearoa/New Zealand: a Kaupapa Māori analysis
}

Tania Huria ${ }^{1 *}$ D, Suetonia Palmer ${ }^{2}$, Lutz Beckert ${ }^{2}$, Jonathan Williman ${ }^{3}$ and Suzanne Pitama ${ }^{1}$

\begin{abstract}
Background: In Aotearoa/New Zealand, Māori, as the indigenous people, experience chronic kidney disease at three times the rate of non-Māori, non-Pacific New Zealanders. Māori commence dialysis treatment for end-stage kidney disease at three times the rate of New Zealand European adults. To examine for evidence of inequity in dialysis-related incidence, treatment practices, and survival according to indigeneity in Aotearoa/New Zealand, utilising a Kaupapa Māori approach.
\end{abstract}

Methods: We conducted a retrospective cohort study involving adults who commenced treatment for end-stage kidney disease in Aotearoa/New Zealand between 2002 and 2011. We extracted data from the Australian and New Zealand Dialysis and Transplant Registry (ANZDATA) linked to the New Zealand National Health Index (NHI). Propensity score methods were used to assemble a cohort of 1039 Mãori patients matched 1:1 on clinical and socio-demographic characteristics with a cohort of 1026 non-Māori patients. We compared incidence of end-stage kidney disease and treatment practices. Differences in the risks of all-cause mortality during treatment between propensity-matched cohorts were estimated using Cox proportional hazards and generalised linear models.

Results: Non-Māori patients were older, more frequently lived in urban areas (83\% versus 67\% [standardised difference 0.38]) and bore less socioeconomic deprivation (36\% living in highest decile areas versus 14\% [0.53]). Fewer non-Māori patients had diabetes (35\% versus 69\%, [- 0.72]) as a cause of kidney failure. Non-Māori patients were more frequently treated with peritoneal dialysis (34\% versus 29\% [0.11]), received a pre-emptive kidney transplant (4\% vs 1\% [0.19]), and were referred to specialist care < 3 months before treatment (25\% vs 19\% [0.15]) than Māori patients. Fewer non-Māori started dialysis with a non-tunnelled dialysis vascular catheter (43\% versus 47\% [-0.08]). The indigenous-age standardised incidence rate ratio for non-Māori commencing renal replacement therapy in 2011 was 0.50 (95\% Cl, 0 . 40-0.61) compared with Māori.

Propensity score matching generated cohorts with similar characteristics, although non-Māori less frequently started dialysis with a non-tunnelled venous catheter (30\% versus 47\% [- 0.35]) or lived remotely (3\% versus 14\% [- 0.50]). In matched cohorts, non-Māori experienced lower all-cause mortality at $5 \mathrm{yr}$. after commencement of treatment (risk ratio $0.78,95 \%$ Cl 0.72-0.84). New Zealand European patients experienced lower mortality than Māori patients in indigenous age-standardised analyses (age-standardised mortality rate ratio $0.58,95 \% \mathrm{Cl} 0.51-0.67$ ).

Conclusions: Non-Māori patients are treated with temporary dialysis vascular access less often than Māori, and experience longer life expectancy with dialysis, even when socioeconomic, demographic, and geographical factors are equivalent. Based on these disparities, health services should monitor and address inequitable treatment practices and outcomes in end-stage kidney disease care.

Keywords: Indigenous, Māori, Disparities, Equity, Dialysis

\footnotetext{
* Correspondence: tania.huria@otago.ac.nz

${ }^{1}$ Māori and Indigenous Health Institute, University of Otago Christchurch, 2

Riccarton Ave, Christchurch 8140, New Zealand

Full list of author information is available at the end of the article
} 


\section{Background}

Chronic kidney disease disproportionally impacts indigenous peoples [1-3]. Inequitable health outcomes for indigenous peoples related to kidney disease and other long-term conditions have not been adequately explained by existing epidemiological approaches. Inequities in health outcomes have persisted despite considerable research and policy efforts, and are entrenched $[2,4]$. An accepted explanation for inequitable outcomes is that increased rates of kidney disease for indigenous peoples are attributable to higher rates of poverty, diabetes, hypertension, and cardiovascular disease $[5,6]$. Studies have also identified socioeconomic deprivation and remote living as putative factors contributing to lower life expectancy and chronic disease risk [1, 7]. It is essential that research methodologies are employed to inform understanding of inequity in the setting of chronic disease [8].

In Aotearoa/New Zealand, Māori, as the indigenous people, experience chronic kidney disease at three times the rate of non-Māori, non-Pacific New Zealanders [3]. Māori commence dialysis treatment for end-stage kidney disease at three times the rate of New Zealand European adults [1, 2, 9, 10]. For example, in 2015, New Zealand European adults incurred an incidence of dialysis nearly four times lower that of Māori adults (72 versus 266 per million population) [11]. It is assumed that disparate treatment practices are driven by comorbidity and socio-economic factors [12]. In contrast to the decreasing incidence of dialysis in nonindigenous populations globally, dialysis rates for Māori have not declined over time $[1,2,9,10]$.

Existing scientific methodologies frame inequity as a deficit present within indigenous peoples and, as such, may not enable researchers and healthcare providers to observe or consider how systemic advantages are sustained for non-indigenous populations within health services [13]. Accordingly, it is possible that nonindigenous research approaches may impede development of policy and health service responses to inequity and prevent health gains for Māori [14]. Given the sustained inequity in health outcomes for Aotearoa/New Zealand, we applied indigenous methodologies to explore for potential sources of inequitable treatment practices and outcomes for Māori with end-stage kidney disease $[14,15]$.

\section{Methods}

\section{Indigenous approach}

We employed a Kaupapa Mãori approach to include the broader political context for research that involves Māori [15]. A Kaupapa Māori approach enabled research practices within this study to enact the principles of the Treaty of Waitangi. This foundational document of Aotearoa/New Zealand from 1840 defines the constitutional relationship between the Treaty partners, the
British Crown and iwi, the governing structures for Māori as the indigenous peoples of Aotearoa/New Zealand [16]. In particular, the research process incorporates Article 3 of the Treaty, that charges the British Crown with the responsibility to provide equity - and therefore health equity - for Māori, as a human right. In recognition of the Treaty partners and this obligation in the study design, we defined Māori and non-Māori as the comparative study cohorts in the primary analysis. We aligned the study methodology with the United Nation Declaration on the Rights of indigenous peoples, and thus included Māori as patients who self-identified as Māori and who were resident in Aotearoa/New Zealand [17].

The Kaupapa Māori approach included utilisation of indigeneity as a 'principle' within the analysis. Indigeneity, when considered as a principle, enabled being Māori to be analysed as marker of risk (for example, risk of exposure to colonisation, poverty, and institutional racism), as opposed to utilising indigeneity as a variable, expressed as a determinant of health practices or outcomes in itself [13]. The Kaupapa Māori methodology incorporated indigenous age standardisation, that utilised the 2013 Māori census population as the reference standardised population, to account for the different age structures of the Māori and non-Māori populations [18, 19].

\section{Study population}

We included all adults (aged $\geq 18$ years) who commenced renal replacement therapy (dialysis or kidney transplantation) as first treatment for end stage kidney disease living in Aotearoa/New Zealand between 1 January 2002 and 31 December 2011 [20]. Patients were censored at the end of the study (31 December 2011), death, or loss to follow up.

\section{Data collection}

We extracted data from ANZDATA and linked these data with the New Zealand National Health Index (NHI) to identify prioritised ethnicity categories and include deprivation and rurality information [21, 22]. Sociodemographic and clinical variables were extracted including: age, gender, ethnicity (labelled in ANZDATA as "racial origin"), postcode, weight, height, medical comorbidities, primary cause of kidney disease (diabetes, hypertension/ischaemic heart disease, glomerulonephritis, polycystic kidney disease, obstruction, and other), late referral to specialist nephrology services (referred $<3$ months before first treatment), dialysis vascular access type (arteriovenous fistula, arteriovenous graft, or central venous catheter [tunnelled or non-tunnelled]), and initial treatment modality at the commencement of renal replacement therapy (haemodialysis, peritoneal dialysis, or kidney transplantation).

We categorised rurality as rural (no or low urban influence), independent urban (minimal major urban 
dependence), and urban (major urban area) [23]. Socioeconomic deprivation indices were drawn from the NZDep2013 [21]. The NZDep2013 deprivation score combines census data relating to income, home ownership, employment, qualifications, family structure, housing, access to transport and communications. A deprivation score is assigned to each meshblock (the smallest geographical area defined by Statistics New Zealand including a population of $60-100$ people) [24, 25]. Deprivation scores are expressed in deciles [26]. A score of one represents areas with the least deprivation and ten the areas with the most. Indigeneity was selfidentified within the National Health Index, which aligned with New Zealand ethnicity data collection protocols [18, 27]. Denominator populations were defined for Māori and non-Māori as the cohort-specific estimated New Zealand resident populations counted on 30 June of the corresponding year [18].

\section{Statistical analysis}

Sociodemographic and clinical characteristics at baseline were summarised as mean and standard deviation for continuous variables and number and proportion for dichotomous variables. Summary baseline characteristics were compared between Māori and non-Māori patients using standardised differences calculated by the Austin formula [28]. Standardised differences of 0.2, 0.5, and 0.8 were considered to represent small, moderate, and large differences between cohorts, respectively.

The primary outcome for the analysis was all-cause mortality. Secondary outcomes were the modality of first treatment and dialysis vascular access type for those commencing haemodialysis.

Propensity score matching was used to assemble Māori and non-Māori cohorts with similar clinical and sociodemographic characteristics to explore differences in the primary and secondary outcomes [28, 29]. Propensity scores were obtained as the predicted probabilities of a logistic regression that included variables that are associated with mortality and dialysis modality. These included: age, gender, body mass index, deprivation score, smoking status and diabetes. Māori patients were matched 1-to-1 with non-Māori patients using a nearest neighbour algorithm [30]. We assessed the balance of characteristics between the matched cohorts before and after matching, expressed as a standardised difference.

We used a Cox proportional hazards model (Breslow method) to evaluate the association of indigeneity with all-cause mortality after commencing dialysis within the propensity score-matched indigenous (Māori) and nonindigenous (non-Māori) cohorts. There was evidence that the hazard for all-cause mortality was not proportional, so we additionally calculated risk ratios of allcause mortality at 1,3 , and 5 years in matched cohorts
(Table 2). As there were differences between the proportion of patients living in urban or rural areas between the propensity-score matched cohorts, all regression analysis of propensity-score matched cohorts were also adjusted for rurality. We used a reverse Kaplan-Meier method to calculate median follow up time [31].

Sensitivity analyses were done within the non-Māori cohort, identifying separate New Zealand European and Pacific cohorts. We then used direct age standardisation within each cohort (Māori, New Zealand European, and Pacific), incorporating Māori as the reference category, to compare age-standardised risk of mortality between groups [19].

Analyses were performed using STATA version 13. The study was approved by the University of Otago Ethics B committee (HD14/27).

\section{Results}

\section{Study population}

Overall, 4781 patients commenced treatment within the study period. Of these, nine patients were excluded due to record duplication. Accordingly, 1459 Māori adults and 3312 non-Māori adults were included in the analysis.

At commencement of treatment with dialysis or transplantation, non-Māori were older ( $58 \pm 15$ years versus 56 \pm 12 years [standardised difference 0.15 ]), and were less likely to smoke (12\% versus $26 \%$ [standardised difference $-0.36])$, have diabetes as cause of kidney disease (35\% versus $69 \%$ [standardised difference -0.72 ]), and had a lower body mass index $\left(28 \pm 7 \mathrm{~kg} / \mathrm{m}^{2}\right.$ versus $33 \pm 8 \mathrm{~kg} / \mathrm{m}^{2}$ [standardised difference-0.67]) (Table 1). Non-Māori more frequently lived in an urban setting (83\% versus $67 \%$ [standardized difference 0.83 ]) and less frequently lived in areas with socioeconomic deprivation (decile 9 and 10: $31 \%$ versus $59 \%$ [standardised difference - 0.59]). After propensity-score matching, the large standardized differences between cohorts for many baseline characteristics were reduced to small standardized differences including: age (0.03), sex (0.04), NZDep13 (0.00), current smoking history $(0.05)$, and diabetes as primary renal disease $(-0.09)$. Despite propensity score matching, non-Māori less frequently lived in a rural area $(-0.52)$.

\section{Incidence of renal replacement therapy}

The annual incidence of commencing renal replacement therapy per million population between 2002 and 2011 is shown in Fig. 1 according to indigeneity. The indigenousage standardised incidence rate ratio for non-Māori commencing renal replacement therapy in 2011 was 0.50 (95\% CI, 0.40-0.61) compared with Māori.

\section{Primary outcome: All-cause mortality}

Patients were followed up for a median of 57.0 months after commencement of dialysis or transplantation. 
Table 1 Baseline characteristics of incident dialysis patients in Aotearoa/New Zealand, according to indigenous status

\begin{tabular}{|c|c|c|c|c|c|c|}
\hline & \multicolumn{3}{|c|}{ Whole Cohort } & \multicolumn{3}{|c|}{ Cohort after propensity matching } \\
\hline & $\begin{array}{l}\text { Non-Māori } \\
n=3312\end{array}$ & $\begin{array}{l}\text { Māori } \\
n=1459\end{array}$ & $\begin{array}{l}\text { Standardised } \\
\text { Difference }\end{array}$ & $\begin{array}{l}\text { Non-Māori } \\
n=1026\end{array}$ & $\begin{array}{l}\text { Māori } \\
n=1039\end{array}$ & $\begin{array}{l}\text { Standardised } \\
\text { Difference }\end{array}$ \\
\hline Age, years $^{a}$ & $58(15)$ & $56(12)$ & 0.15 & $55(13)$ & $55(12)$ & 0.03 \\
\hline Women $^{a}$ & $1310(40)$ & $601(41)$ & -0.02 & $564(39)$ & $595(41)$ & -0.04 \\
\hline \multicolumn{7}{|l|}{ Domicile Code } \\
\hline Urban & $2728(83)$ & $981(67)$ & 0.38 & $1270(88)$ & $974(67)$ & 0.52 \\
\hline Semi-urban & $342(10)$ & $268(18)$ & -0.23 & $130(9)$ & $264(18)$ & -0.27 \\
\hline Rural & $234(7)$ & $206(14)$ & -0.23 & $45(3)$ & $206(14)$ & -0.50 \\
\hline \multicolumn{7}{|l|}{ Deprivation score ${ }^{a}$} \\
\hline 1 to 5 & $1184(36)$ & $206(14)$ & 0.53 & $202(14)$ & $205(14)$ & 0.00 \\
\hline 6 to 8 & $1086(33)$ & $396(27)$ & 0.13 & $426(29)$ & $393(27)$ & 0.04 \\
\hline 9 to 10 & $1034(31)$ & $854(59)$ & -0.59 & $817(57)$ & $847(59)$ & -0.04 \\
\hline \multicolumn{7}{|l|}{ Smoking status ${ }^{a}$} \\
\hline Never & $1663(50)$ & $406(28)$ & 0.46 & $441(31)$ & $402(28)$ & 0.07 \\
\hline Former & $1243(38)$ & $679(47)$ & -0.18 & $652(45)$ & $671(46)$ & -0.02 \\
\hline Current & $404(12)$ & $373(26)$ & -0.36 & $352(24)$ & $372(26)$ & -0.05 \\
\hline \multicolumn{7}{|l|}{ Laboratory variables } \\
\hline Serum creatinine $\mu \mathrm{mol} / \mathrm{L}$ & $721(333)$ & $783(350)$ & -0.18 & $753(322)$ & $782(350)$ & -0.09 \\
\hline Haemoglobin, g/L & $110(17)$ & $108(17)$ & 0.12 & $109(17)$ & $108(17)$ & 0.06 \\
\hline Body mass index $\mathrm{kg} / \mathrm{m}^{2 a}$ & $28(7)$ & $33(8)$ & -0.67 & $33(9)$ & $33(8)$ & 0.00 \\
\hline \multicolumn{7}{|l|}{ Primary renal disease } \\
\hline Diabetes $^{a}$ & $1143(35)$ & $1010(69)$ & -0.72 & $940(65)$ & $1001(69)$ & -0.09 \\
\hline Hypertension/ischaemic & $446(14)$ & $80(5)$ & 0.31 & $88(6)$ & $79(5)$ & 0.04 \\
\hline Glomerulonephritis & $941(28)$ & $228(16)$ & 0.29 & $250(17)$ & $228(16)$ & 0.03 \\
\hline Polycystic kidney disease & $241(7)$ & $23(2)$ & 0.24 & 37 (3) & $22(2)$ & 0.06 \\
\hline Urological & $146(4)$ & $25(2)$ & 012 & $35(2)$ & $25(2)$ & 0.00 \\
\hline Other & $395(12)$ & $93(6)$ & 0.21 & $95(7)$ & $90(6)$ & 0.04 \\
\hline \multicolumn{7}{|l|}{ Comorbid medical conditions } \\
\hline \multicolumn{7}{|l|}{ Diabetes } \\
\hline Type 1 & $116(4)$ & $27(2)$ & 0.12 & $69(5)$ & $27(2)$ & 0.16 \\
\hline Type 2 & $1241(37)$ & $1042(72)$ & -0.75 & $1014(70)$ & $1033(71)$ & -0.02 \\
\hline Coronary artery disease & $875(26)$ & $410(28)$ & -0.05 & $415(29)$ & $402(28)$ & 0.02 \\
\hline Peripheral vascular disease & $458(14)$ & $281(19)$ & -0.14 & $260(18)$ & $273(19)$ & -0.03 \\
\hline Cerebrovascular disease & $373(11)$ & $156(11)$ & 0 & $181(13)$ & $153(11)$ & 0.06 \\
\hline Chronic lung disease & $354(11)$ & $275(19)$ & -0.23 & $196(14)$ & $273(19)$ & -0.14 \\
\hline Cancer & $692(21)$ & $204(14)$ & 0.19 & $192(13)$ & $203(14)$ & -0.03 \\
\hline \multicolumn{7}{|c|}{ Year of starting renal replacement therapy } \\
\hline $2002-2003$ & $609(18)$ & $282(19)$ & -0.03 & $260(18)$ & $274(19)$ & -0.03 \\
\hline 2004-2006 & $955(29)$ & $430(30)$ & -0.02 & $366(25)$ & $393(27)$ & -0.05 \\
\hline $2007-2008$ & $643(19)$ & $289(20)$ & -0.03 & $366(25)$ & $413(29)$ & -0.09 \\
\hline 2009-2011 & $1105(34)$ & $458(31)$ & 0.06 & $453(31)$ & $365(25)$ & 0.13 \\
\hline
\end{tabular}

Data are presented as number (proportion) or mean (SD). Standardised differences of 0.2, 0.5 and 0.8 can be considered to represent small, medium and large differences [25, 38]. Deprivation based on NZDep13 which is a socio economic deprivation index used in Aotearoa/New Zealand where $10=$ lowest decile (most deprived) and $1=$ highest decile (least deprived) [19]. Urban is defined as most urbanised areas of Aotearoa/New Zealand, semi-urban is defined as towns and

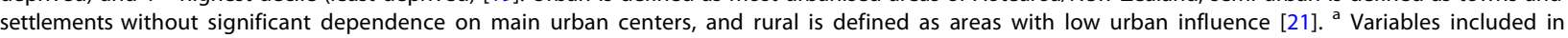
the propensity score modeling 


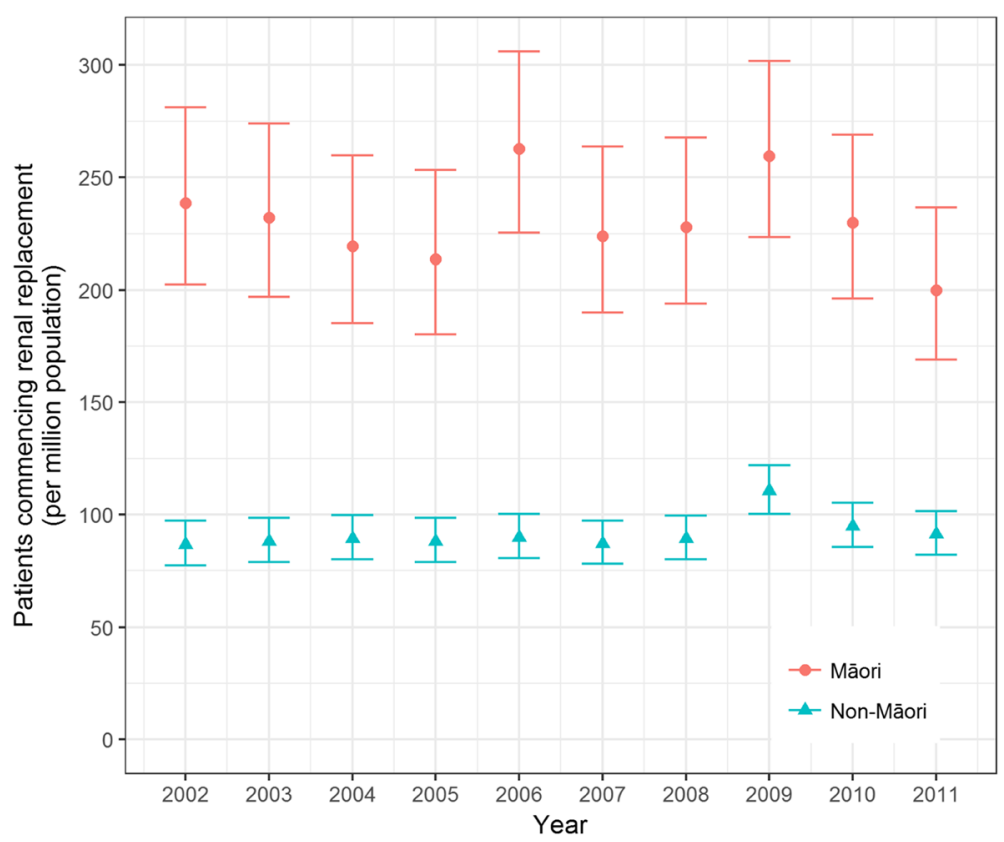

Fig. 1 Incidence rates for commencing renal replacement therapy

There were 2284 deaths (1465 non-Māori and 847 Māori). After propensity score matching, there were 1186 deaths during follow up including 513 for nonMāori and 673 for Māori.

In unadjusted analysis, the risk of all-cause mortality was lower for non-Māori (unadjusted hazard ratio [HR] $0.82,95 \% \mathrm{CI}, 0.75-0.89$ ). In survival analysis comparing the propensity score matched cohorts, non-Māori had a lower risk of mortality (HR $0.68,95 \%$ CI $0.61-0.76$ ) (Fig. 2). There was no evidence of a different risk of allcause mortality between non-Māori and Māori at 1 year after starting therapy) (Table 2). Non-Māori experienced a lower risk of all-cause mortality than Mãori at
3 and 5 years after commencing treatment and adjusted for rurality.

\section{Secondary outcomes: Treatment practices}

Treatment practices for renal replacement therapy are shown in Table 3. Non-Māori were less frequently referred late to specialist renal services (19\% versus $25 \%$ [standardised difference - 0.15]). Non-Māori were more frequently treated with peritoneal dialysis (34\% versus $29 \%$ [0.11]) or access pre-emptive kidney transplantation (4\% versus $1 \%$ [0.17]). Fewer non-Māori started dialysis with a non-tunnelled dialysis vascular catheter $(43 \%$ versus $47 \%[-0.08]$ ) and more experienced a functioning

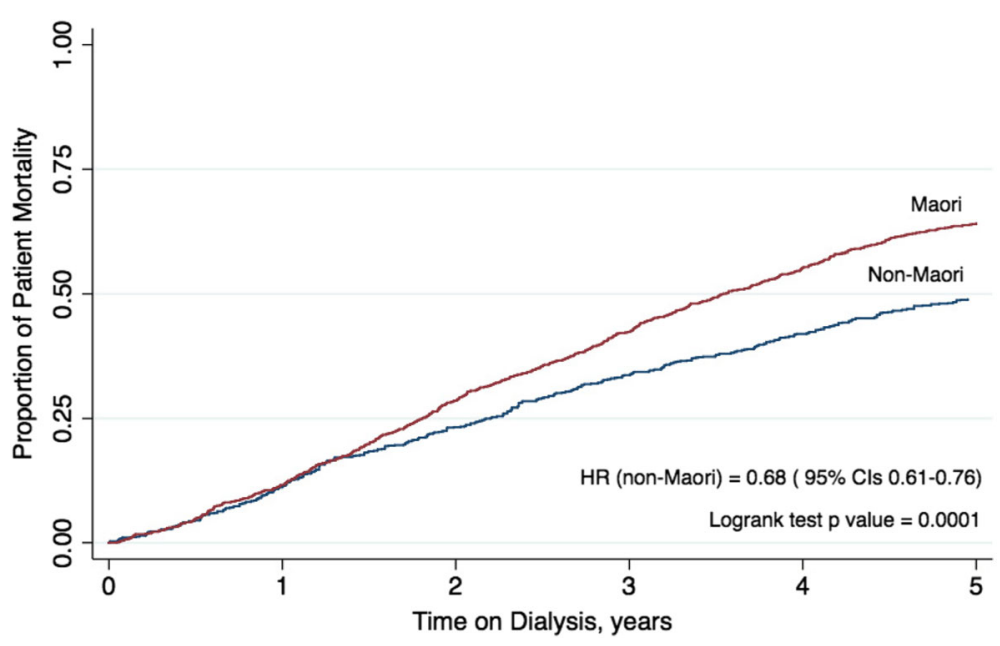

Fig. 2 Kaplan Meier of propensity score matched cohort of mortality by indigeneity and the number of years on renal replacement therapy 
Table 2 All-cause mortality at 1, 3, and 5 years after commencing treatment for end-stage kidney disease according to indigenous status

\begin{tabular}{llll}
\hline $\begin{array}{llll}\text { Indigenous status, } \\
\text { deaths }(\%)\end{array}$ & \multicolumn{3}{l}{ Years since commencement of dialysis } \\
\cline { 2 - 4 } & One & Three & Five \\
\hline Māori $(N=1039)$ & $122(11.7)$ & $444(42.7)$ & $673(64.8)$ \\
Non-Māori $(N=1026)$ & $120(11.7)$ & $353(34.4)$ & $513(50.0)$ \\
Risk ratio $^{a}$ & 1.07 & 0.83 & 0.78 \\
$(95 \% \mathrm{Cl})$ & $(0.83-1.38)$ & $(0.74-0.93)$ & $(0.72-0.84)$ \\
\hline
\end{tabular}

${ }^{\mathrm{a}}$ Non-Mãori vs Mãori. Risk ratios are adjusted for rurality

arteriovenous fistula at dialysis start (26\% versus $23 \%$ [standardised difference 0.07]). Despite propensity matching, fewer non-Māori patients commenced dialysis with a non-tunnelled central venous catheter (standardised difference -0.35) and the standardized difference in peritoneal dialysis as a first treatment modality was reduced to $(0.00)$.

\section{Sensitivity analyses}

In sensitivity analysis and to obtain indigenous agestandardization for all-cause mortality, we further disaggregated the non-Māori cohort into New Zealand European $(n=1814)$, Pacific $(n=929)$, and other ethnicities $(n=433)$ (Table 4). Indigenous age-standardization led to an adjusted mortality rate ratio for Māori of 1.72 (95\% CI 1.50-1.97) compared with New Zealand European. Pacific patients experienced a higher agestandardized mortality rate ratio than NZ European (1.33, 95\% CI 1.16-1.52) but the rate ratio remained lower compared with Māori (1.38 95\% CI 1.27-1.51).

\section{Discussion}

A Kaupapa Māori approach to exploring inequity enabled use of best practice ethnicity protocols, incorporated the obligations of the Treaty of Waitangi toward health equity, and adjusted for complex sociodemographic factors and indigenous age standardisation. Using a Kaupapa Māori analysis, this study demonstrates persistent inequity in dialysis incidence, mortality, and treatment practices for patients in Aotearoa/New Zealand. Even when sociodemographic characteristics, comorbidity, and referral practices are equivalent, nonMāori patients less frequently receive non-tunnelled dialysis vascular access when starting dialysis treatment and experience lower mortality risk at 3 and 5 years after starting treatment. These differences in incidence, treatment practices and mortality during treatment for endstage kidney disease suggest that healthcare systems for dialysis sustain inequitable practices and survival outcomes for Māori. Temporary vascular access is associated with lower survival and increased infection-related morbidity [32]; therefore the lower use of temporary vascular access for non-Māori after controlling for comorbidity to specialist services warrants further scrutiny.

These findings are consistent with observations made by other investigators showing that non-Mãori receive higher quality care within New Zealand healthcare services [33], including lower rates of unplanned hospital readmission and death within 30 days [34]. New Zealand European patients are less likely to experience racism and discrimination, factors that are associated with poorer mental and physical health [35]. The better

Table 3 Baseline treatment practice characteristics

\begin{tabular}{|c|c|c|c|c|c|c|c|c|c|c|}
\hline \multirow[b]{2}{*}{ Treatment Practices } & \multicolumn{5}{|c|}{ Whole Cohort } & \multicolumn{5}{|c|}{ Propensity Matched Cohort } \\
\hline & $\begin{array}{l}\text { Non-Māori, } \\
n(\%) \\
n=3312\end{array}$ & $\begin{array}{l}\text { Māori, } \\
\mathrm{n}(\%) \\
n=1459\end{array}$ & Risk ratio & $95 \% \mathrm{Cl}$ & $\begin{array}{l}\text { Standardised } \\
\text { difference }\end{array}$ & $\begin{array}{l}\text { Non-Māori, } \\
n(\%) \\
n=1026\end{array}$ & $\begin{array}{l}\text { Māori, } \\
\mathrm{n}(\%) \\
n=1039\end{array}$ & Risk Ratio & $95 \% \mathrm{Cl}$ & $\begin{array}{l}\text { Standardised } \\
\text { difference }\end{array}$ \\
\hline \multicolumn{11}{|l|}{ Modality of first treatment } \\
\hline Peritoneal Dialysis & $1110(34)$ & $420(29)$ & 1.16 & $1.06-1.28$ & 0.11 & $420(29)$ & $418(29)$ & 1.02 & $0.92-1.13$ & 0 \\
\hline Haemodialysis & $2063(62)$ & $1027(70)$ & 0.88 & $0.85-0.92$ & -0.17 & $998(69)$ & $1015(70)$ & 0.99 & $0.97-1.00$ & -0.02 \\
\hline Transplant & $139(4)$ & $12(1)$ & 5.10 & $2.84-9.17$ & 0.19 & $27(2)$ & $12(1)$ & 2.28 & $1.16-4.47$ & 0.08 \\
\hline \multicolumn{11}{|l|}{ *Haemodialysis vascular access } \\
\hline Arteriovenous fistula & $468(26)$ & $206(23)$ & 1.12 & $0.97-1.30$ & 0.07 & $224(26)$ & $205(23)$ & 1.12 & $0.95-1.32$ & 0.07 \\
\hline Arteriovenous graft & $21(1)$ & $18(2)$ & 0.58 & $0.31-1.08$ & -0.08 & $11(1)$ & $18(2)$ & 0.62 & $0.30-1.31$ & -0.08 \\
\hline $\begin{array}{l}\text { Tunnelled central venous } \\
\text { catheter }\end{array}$ & $546(30)$ & $247(28)$ & 1.09 & $0.96-1.24$ & 0.04 & $288(33)$ & $242(28)$ & 1.22 & $1.05-1.40$ & 0.11 \\
\hline $\begin{array}{l}\text { Non-tunnelled central } \\
\text { venous catheter }\end{array}$ & $766(43)$ & $419(47)$ & 0.90 & $0.83-0.99$ & -0.08 & $337(30)$ & $414(47)$ & 0.83 & $0.75-0.93$ & -0.35 \\
\hline \multicolumn{11}{|l|}{ Referral practices } \\
\hline $\begin{array}{l}\text { Referral to specialist services } \\
\text { within } 3 \text { months of starting } \\
\text { treatment }\end{array}$ & $620(19)$ & $371(25)$ & 0.74 & $0.65-0.82$ & -0.15 & $365(25)$ & $293(20)$ & 1.26 & $1.11-1.43$ & 0.12 \\
\hline
\end{tabular}

*The difference in population sample size between the whole cohort and for vascular access is due to missing data collection of vascular access data at clinical sites. There was $n=1801$ non-Māori and $n=890$ Māori with baseline data for dialysis vascular access (and $n=860$ and $n=879$ included in propensity score matched cohorts) 
Table 4 Mortality outcomes during treatment for end-stage kidney disease according to indigenous status in Aotearoa/New Zealand

\begin{tabular}{llllllll}
\hline Ethnicity & Patients, $\mathrm{n}$ & $\begin{array}{l}\text { Follow-up } \\
\text { (person-years) }\end{array}$ & Deaths, $\mathrm{n}$ & $\begin{array}{l}\text { Crude mortality rate } \\
\text { (per 100 person-years) }\end{array}$ & $\begin{array}{l}\text { Age standardized mortality } \\
\text { rate (per 100 person-years) }\end{array}$ & $\begin{array}{l}\text { Crude mortality } \\
\text { rate ratio }\end{array}$ & $\begin{array}{l}\text { Indigenous age-standardised } \\
\text { mortality rate ratio (95\% Cl) }\end{array}$ \\
\hline Māori & 1459 & 4.84 & 847 & 12 & 8.4 & 1.32 & $1.72(1.50-1.97)$ \\
Pacific & 929 & 4.15 & 389 & 10.1 & 6.5 & 1.11 & $1.33(1.16-1.52)$ \\
New Zealand & 1814 & 4.92 & 810 & 9.1 & 4.9 & 1.00 (ref) & 1.00 (ref)
\end{tabular}

European

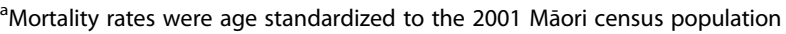

dialysis-related practices and clinical outcomes for nonMāori in this current study are also consistent with recent findings showing that dialysis treatment continues to benefit non-indigenous Australians with greater access to home based dialysis and preferred dialysis modalities than for indigenous Australians [13]. Taken together with the existing literature, our findings add to the growing body of evidence that renal health services in New Zealand advantage non-Māori patients and sustain health inequities.

In practice, policy makers and dialysis services need to consider appropriate interventions to ensure equitable access to quality care for end stage kidney disease. Specifically, health services should ensure that dialysis services provide access to peritoneal dialysis and preemptive transplantation for Māori and non-Māori, and early referral to specialist services for patients who require renal replacement therapy. Policy makers and clinicians need to identify effective ways to enable timely permanent dialysis vascular access, and practices that are associated with better outcomes for patients on renal replacement therapy including home based care, longer hours' dialysis, and kidney transplantation. Further work within renal services is needed to identify interventions that ensure inequitable practices and outcomes including sustainable access to preferred treatment options.

In a previous action research study, changes to health systems at the community and family/whānau, health practitioner, and health service level were identified to address inequity in heart disease management (including systems to support access to hospital appointments, prehospital fibrinolytic therapy, and strategy planning for disease prevention) [36]. In dialysis care, and based on the findings in the present study, potential actions might include supporting greater access to permanent vascular access and kidney transplantation, and identifying quality improvement activities to reduce morbidity for dialysis patients. Addressing inequity in healthcare also requires setting expectations that organisations will deliver equity as a measure of quality care, embed health inequity interventions within operating policies, and monitor care quality regularly [37]. In practice, this could include regular monitoring of outcomes for Māori and non-Māori with end-stage kidney disease. In addition, policy-makers and clinicians need to consider effective innovations that advance Māori health outcomes, including community initiated interventions [7, 36-38].

While the strengths of the study included a Kaupapa Māori approach, propensity score matching to account for comorbidities and demographics, a large population dataset (ANZDATA) and indigenous age standardisation, the study has limitations which need to be considered when interpreting the results. First, this is a retrospective study and variables which have been shown in other studies to be associated with Māori and non-Māori life expectancy were not directly accounted for, such as housing [7], education, and income [18]. This may have resulted in residual bias in the results, although the study included the NZDep2013 deprivation score to account for a range of complex socioeconomic factors associated with specific rurality. Second, the study design did not account for time-varying exposure to risk factors for survival such as dialysis-related complications and comorbidity. Third, the use of the National Health Index number to identify participant rurality to identify rurality and deprivation is limited due to the rurality code defaulting to the nearest postal service centre, which may result in bias relating to geographical and deprivation ascertainment. Fourth, neither interactions nor subgroup analysis were used to explore differences in the effect of indigeneity upon mortality in this population. However, there is evidence in the literature that the gap in life-expectancy between Māori and nonMāori in New Zealand differs according to age and smoking status, and these interactions should be included in future research [39]. Finally, this study did not measure access to home based therapy, adjust for hours of dialysis per week, or record or explore treatment adherence.

\section{Conclusions}

This Kaupapa Māori analysis demonstrated that nonMāori patients were less likely to start dialysis, less frequently received non-tunnelled vascular access when starting dialysis, and experienced better survival during treatment for end-stage kidney disease. Non-Māori are advantaged by better treatment outcomes in New Zealand renal care, even when socioeconomic, clinical, 
and geographical factors are equivalent. Health services and policies need to consider indigeneity as a marker of exposure to risk factors for adverse outcomes in renal care, that warrant action and monitoring, as ways to address disparities in renal care in Aotearoa/New Zealand.

\section{Abbreviations}

ANZDATA: Australia New Zealand Dialysis and Transplantation Registry;

Cl: Confidence Intervals; HR: Hazard Ratio; NHI: National Health Index;

NZDep: New Zealand Index of Deprivation

\section{Acknowledgements}

ANZDATA is funded by the Australian Organ and Tissue Donation and Transplantation Authority, the NZ Ministry of Health, and Kidney Health Australia. The authors wish to acknowledge the sharing of data by patients and whānau.

\section{Funding}

TH receives support from a Health Research Council of New Zealand Māor PhD scholarship. SCP receives a Rutherford Discovery Fellowship from the Royal Society of New Zealand.

\section{Availability of data and materials}

The data that support the findings of this study are available from ANZDATA but restrictions apply to the availability of these data, which were used under license for the current study, and so are not publicly available.

\section{Authors' contributions}

Study concept: TH, SCP, SGP. Study design: TH, JW, SCP, SGP. Data collection: TH Data analysis: TH, SCP, JW. Data interpretation: All authors. Drafting of the reporting: TH. Reviewing of manuscript for intellectual content: All authors. All authors agreed on the final paper for publication. All authors read and approved the final manuscript.

\section{Ethics approval and consent to participate}

The study was approved by the University of Otago Ethics B committee before data were obtained (HD14/27). All patients whom have information collected via ANZDATA have given their consent for data to be collected and utilised for research purposes. All research requests via ANZDATA are subject to peer-review, and if the data application meets ANZDATA criteria data requests are approved.

\section{Consent for publication}

Not applicable.

\section{Competing interests}

The authors declare they have no competing interests.

\section{Publisher's Note}

Springer Nature remains neutral with regard to jurisdictional claims in published maps and institutional affiliations.

\section{Author details}

'Māori and Indigenous Health Institute, University of Otago Christchurch, 2 Riccarton Ave, Christchurch 8140, New Zealand. ${ }^{2}$ Department of Medicine, University of Otago Christchurch, Christchurch, New Zealand. ${ }^{3}$ Department of Population Health, University of Otago Christchurch, Christchurch, New Zealand.

Received: 17 October 2017 Accepted: 4 February 2018

Published online: 20 February 2018

\section{References}

1. Jha V, et al. Chronic kidney disease: global dimension and perspectices. Lancet. 2013;382:260-72

2. Naqshbandi M, Harris SB, Esler JG, Antwi-Nsiah F. Global complication rates of type 2 diabetes in indigenous peoples: a comprehensive review. Diabetes Res Clin Prac. 2008;82:1-17.
3. Stewart JH, MR MC, SP MD. The incidence of end-stage renal disease in New Zealand Maori and Pacific Island people and in indigenous Australians. Nephol Dial Transplant. 2004;19:678-85.

4. Lawton $P$, et al. Survival of indigenous Australians receiving renal replacement therapy: closing the gap? Med J Aust. 2015;4:200-2005.

5. Yeates K, Tonelli M. Indigenous health: update on the impact of diabetes and chronic kidney disease. Curr Opin Nephrol Hypertens. 2006;15(6):588-92

6. Norris KC, Agodoa LY. Unraveling the racial disparities associated with kidney disease 1. Kidney Int. 2005;68(3):914-24.

7. Howden-Chapman P, et al. Effect of insulating existing houses on health inequality: cluster randomised study in the community. Br Med J. 2007; 334(7591):460

8. Reid $\mathrm{P}$, et al. Achieving health equity in Aotearoa: strengthening responsiveness to Māori in health research. The New Zealand Medical Journal. 2017;130(1465):96-103.

9. Grace BS, Clayton P, McDonald S. Increases in renal replacement therapy in Australia and New Zealand: understanding trends in diabetic nephropathy. Nephrology. 2012:17(1):1440-797.

10. Palmer S. New Zealand dialysis and transplantation audit 20012-2013. Board, Editor: N.R.A; 2015.

11. Australia and New Zealand Dialysis and Transplant (ANZDATA) Registry. ANZDATA Registry 39th annual report 2016. Adelaide: ANZDATA; 2016.

12. Walker R, et al. Māori patients' experiences and perspectives of chronic kidney disease: a New Zealand qualitative interview study. BMJ Open. 2017; 7(1):e01382.

13. Walter $M$, Andersen C. Indigenous statistics: A quantitative research methodology. Oxford: Routledge; 2013.

14. Anderson I, et al. Indigenous and tribal peoples' health (The Lancet-Lowitja Institute Global Collaboration): a population study. Lancet. 2016;388(10040): 131-57.

15. Smith LT. Decolonising methodologies: research and indigenous peoples. ed. Z.B. Ltd.; 2013

16. CERD. Consideration of reports submitted by states parties under article 9 of the convention - concluding observations of the committee on the elimination of racial discrimination. New Zealand. 71st session. Geneva: United Nations; 2007.

17. United Nations. Declaration on the Rights of Indigenous Peoples. [cited 201720 April 2017]; Available from: https://http://www.un.org/ development/desa/indigenouspeoples/declaration-on-the-rights-ofindigenous-peoples.html.

18. Robson B, Harris R. Hauora: Màori standards of health IV. A study of the years 2000-2005. Wellington: Te Ropu Rangahau Hauora a Eru Pomare; 2007.

19. Robson B, et al. Age standardisation-an indigenous standard? Emerg Themes Epidemiol. 2007:4(1):3.

20. Smith L. Decolonising methodologies: research and indigenous peoples. Second ed. London: Zed Books; 2012

21. Atkinson J, Salmond C, Cramption J, NZDep2013 Index of Deprivation. Division of Health Sciences, University of Otago: Department of Public Health. Wellington: University of Otago; 2014.

22. New Zealand Ministry of Health. National Health Index. 2012. [cited 2017; Available from: https://www.health.govt.nz/our-work/health-identity/ national-health-index.

23. Statistics New Zealand. 2015; Available from: http://archive.stats.govt.nz/ browse for stats/Maps and geography/Geographic-areas/urban-ruralprofile-update.aspx.

24. Atkinson J, Salmond C, Crampton P. NZDep2013 index of deprivation. Dunedin: University of Otago; 2014

25. Salmond CE, Crampton P. Development of New Zealand's deprivation index (NZDep) and its uptake as a national policy tool. Can J Public Health. 2012: S7-S11.

26. ANZDATA. Australia and New Zealand dialysis and transplantation registry (ANZDATA). 2017. Available from: http://www.anzdata.org.au/v1/index.html.

27. Page $M$, et al. Accuracy of ethncity data recorded in hospital-based patient clinical records and the Australia and New Zealand dialysis and transplant registry. N Z Med J. 2017;130(1454):65-71.

28. Austin PC. Balance diagnostics for comparing the distribution of baseline covariates between treatment groups in propensity-score matched samples. Stat Med. 2009;28:3083-107.

29. Rosenbaum PR, Rubin DB. The central role of the propensity score in observational studies for causal effects. Biometrika. 1983;70:41-55. 
30. Austin PC. An introduction to propensity score methods for reducing the effects of confounding in observational studies. Multivariate Behav Res. 2011;46(3):399-424.

31. Shanyinde M. Common misunderstandings of survival time analysis. University of Oxford: Centre for Statistics in Medicine; 2012.

32. Ethier J, et al. Vascular access use and outcomes: an international perspective from the dialysis outcomes and practice patterns study. Nephrol Dial Transplant. 2008;23(10):3219-26.

33. Davis $\mathrm{P}$, et al. Quality of hospital care for Māori patients in New Zealand: retrospective cross-sectional assessment. Lancet. 2006;367(9526):1920-5.

34. Rumball-Smith J, et al. Ethnic disparities in the quality of hospital care in New Zealand, as measured by 30-day rate of unplanned readmission/death. Int J Qual Health Care. 2013(mzt012).

35. Harris $R$, et al. Racism and health: the relationship between experience of racial discrimination and health in New Zealand. Sco Sci Med. 2006;63(6): 1428-41.

36. Kerr S, et al. Kaupapa Maori action research to improve heart disease services in Aotearoa, New Zealand. Ethn Health. 2010;15(1):15-31.

37. Ministry of Health. Equity of health Care for Māori: a framework. Wellington: Ministry of Health; 2014

38. Whittaker $\mathrm{R}$, et al. A multimedia mobile phone-based youth smoking cessation intervention: findings from content development and piloting studies. J Med Internet Res. 2008;10(5)::49.

39. Carter K, Blakely T, Soeberg M. Trends in survival and life expectancy by ethnicity, income and smoking in New Zealand. NZ Med J. 2010;123(1320): 13-24.

\section{Submit your next manuscript to BioMed Central and we will help you at every step:}

- We accept pre-submission inquiries

- Our selector tool helps you to find the most relevant journal

- We provide round the clock customer support

- Convenient online submission

- Thorough peer review

- Inclusion in PubMed and all major indexing services

- Maximum visibility for your research

Submit your manuscript at www.biomedcentral.com/submit

) Biomed Central 